\title{
Use of existing networks for post-market monitoring?
}

\author{
K. Schmidt', W. Mönkemeyer ${ }^{1}$, P. Böttinger ${ }^{2}$, R. Wilhelm², and J. Schiemann ${ }^{2}$ \\ ${ }^{1}$ BioMath GmbH, Rostock \\ ${ }^{2} \mathrm{JKI}$, Braunschweig
}

Eingegangen: 2. Dezember 2008

Council Decision 2002/811/EC, Annex C 1.7. proposes to extend existing monitoring or general surveillance systems to potential adverse effects arising from the placing on the market of GMOs. In a common research project coordinated by the JKI we analysed two different approaches for using these networks and combining the information with the data from farm questionnaires as the main tool of GMO monitoring. In Germany we found about 100 agricultural and environmental observation programs and assessed them according to well- defined criteria like geographical extension, protection goals, data quality, etc. Since these networks vary extremely in their concepts and data structure we conclude that a raw data combination and common analysis is no option for their use. Moreover we propose to work with the reports published by these networks, and to centrally analyse them for potential causes of the reported trends or effects. This could be managed by a Central Reporting Office where also effects arising from GMO cultivation could be identified.

To access this journal online:

http://www.birkhauser.ch/JVL 